\title{
APRENDIZAGEM COLABORATIVA DESENVOLVIDA EM AMBIENTES VIRTUAIS
}

\section{Collaborative Learning Developed in Virtual Environments}

\author{
Rafael Scheffer Pacheco * \\ Regis Alexandre Lahm ** \\ João Bernardes da Rocha Filho ***
}

\begin{abstract}
Resumo: O presente artigo descreve uma investigação que avaliou a utilização de ambientes virtuais de aprendizagem colaborativa no processo de construção de conhecimentos sobre ciências da natureza em um grupo de 16 estudantes do terceiro ano do ensino médio de uma escola pública localizada na região metropolitana de Porto Alegre. A pesquisa teve abordagem qualitativa do tipo estudo de caso e os relatos coletados foram analisados por Análise Textual Discursiva (ATD), com categorias emergentes. $\mathrm{O}$ ambiente virtual utilizado foi disponibilizado pela empresa Microsoft ${ }^{\circledR}$ na plataforma OneDrive ${ }^{\circledR}$. Os participantes identificaram contribuições proporcionadas pelo uso do ambiente virtual e da tecnologia em sala de aula, assinalando seus benefícios para o processo educacional. Entre os argumentos encontrados nas respostas dos participantes, estão os seguintes: o aumento da mobilidade proporcionada pelos recursos tecnológicos; a capacidade de a virtualidade possibilitar o surgimento de múltiplos processos de experimentação; a redução da sensação de distanciamento dos educandos entre si, e destes em relação ao professor; a superação dos limites impostos pelo tempo e espaço da sala de aula transmissiva e; a potencialização do questionamento reconstrutivo, à medida que os recursos para a busca de informações ficam à disposição e podem ser prontamente acessados e questionados pelo grupo de colaboração. Como resultado, a investigação permitiu concluir que os participantes reconhecem que a aprendizagem colaborativa em ambientes virtuais possibilita a implementação de uma forma prática de educação pela pesquisa, pois se desenvolve ao longo de um processo que implica interação com fontes de consulta e com grupos de trabalho, abrindo a possibilidade do surgimento de novas compreensões e relações.
\end{abstract}

Palavras-chave: Aprendizagem colaborativa. Ambientes virtuais.

\begin{abstract}
This paper describes an investigation that evaluated the use of collaborative learning virtual environments in the process of building knowledge about natural sciences in a group of 16 third year high school students from a public school located in the metropolitan region of Porto Alegre. The research had a qualitative approach of the case study type and the collected reports were analyzed by Discursive Textual Analysis (ATD), with emerging categories. We used an available Microsoft ${ }^{\circledR}$ on the OneDrive ${ }^{\circledR}$ platform like virtual environment. Participants identified contributions provided by the use of the virtual environment and technology in the

\footnotetext{
* Mestre em ensino de ciências pela PUCRS - PPGEDUCEM, https://orcid.org/0000-0003-3207-2925. E-mail: prof.rafaelscheffer@gmail.com

** Professor Doutor da Escola Politécnica- EP, curso de Geografia e PPGEDUCEM-PUCRS, ORCID: https://orcid.org/0000-0002-1102-5655.E-mail: lahm@pucrs.br

*** Professor Doutor e Titular da Escola Politécnica- EP, curso de Física e PPGEDUCEM-PUCRS, https://orcid.org/0000-0002-5058-3107 E-mail: jbrfilho@pucrs.br
} 

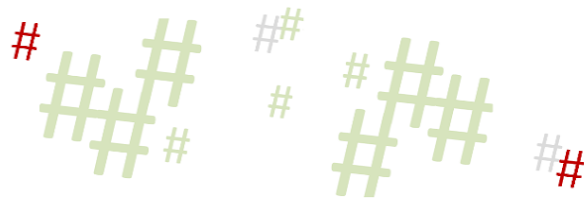

classroom, highlighting their benefits to the educational process. The arguments found in the participants' answers are the following: increased mobility provided by technological resources; ability of virtuality to enable the emergence of multiple processes of experimentation; reduction of the feeling of distance between the students and each other in relation to the teacher; overcoming the limits imposed by the time and space of the transmissive classroom and; enhancement of reconstructive questioning, as resources for information seeking are available and can be readily accessed and questioned by the collaboration group. As a result, the research concluded that participants recognize that collaborative learning in virtual environments enables the implementation of a practical form of research education, as it develops along a process that involves interaction with consultation sources and working groups, opening the possibility of the emergence of new understandings and relationships.

Keywords: Collaborative learning. Virtual environments.

\section{Introdução}

O processo de aprendizagem colaborativa possibilita a construção de conhecimentos a partir de trabalhos em equipe, quando o educando interage e modifica os significados do grupo, gerando a possibilidade de que novas compreensões e relações sejam estabelecidas (TORRES; ALCANTARA; IRALA, 2004), e esse tipo de aprendizagem pode ser potencializado por meio das tecnologias de informação e comunicação (VARELLA et al. 2002). Em vista disso, a investigação descrita neste artigo procurou avaliar as formas pelas quais essa potencialização ocorre, visando a contribuir para que trabalhos pedagógicos com vieses colaborativos e virtuais se tornem cada vez mais compreendidos e possam ser mais bem utilizados no âmbito do ensino médio.

Para isso, é essencial que os professores se atualizem frente às novas tecnologias, de modo que possam bem utilizar esses recursos tecnológicos, tornando o espaço escolar mais atrativo e produtivo relativamente aos fins educacionais de preparação para o exercício da cidadania plena (FREITAS, 2010; COUTINHO; LISBÔA, 2011). Trata-se de um desafio à escola do século XXI introduzir amplamente o uso das tecnologias na aprendizagem, em um processo de modernização esperado há muito. Isso é adequado, posto que:

\footnotetext{
Este sistema permite que los alumnos se familiarizen con el uso de la tecnología que viene, les da acceso a los materiales de clase desde cualquier computadora conectado a la red, les permite mantener la clase actualizada con últimas publicaciones de buenas fuentes, y especialmente en los casos de clases numerosas, los alumnos logran comunicarse aun fuera del horario de clase sin tener que concurrir a clases de consulta, pueden compartir puntos de vista con compañeros de clase, y llevar a cabo trabajos en grupo (SCAGNOLI, 2000, p. 2).
}

Apesar de que se pode afirmar que a escola pouco mudou ao longo das últimas décadas (SIQUEIRA; PESSANHA; SILVA, 2016), essa é uma afirmação que se refere mais ao estilo transmissivo, à rotina e às regras disciplinares praticadas no ambiente escolar do que propriamente às tecnologias. Aliás, o século $\mathrm{XX}$ foi marcado pela introdução de diversas tecnologias nos sistemas de ensino (ALTOÉ; SILVA, 2005), como o mimeógrafo, o retroprojetor, o rádio, a televisão, o gravador de voz, os projetores de slides e de filmes, as câmeras de vídeo e os reprodutores de VHS, o quadro branco e as canetas marcadoras, as 

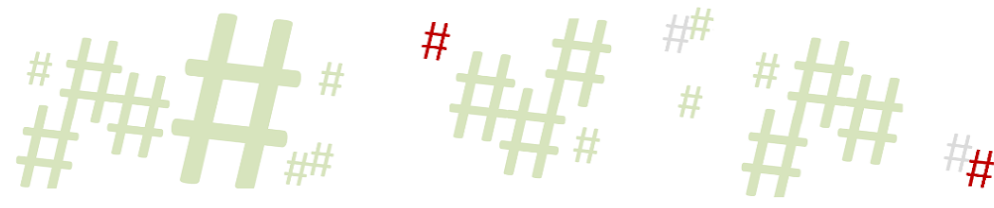

calculadoras eletrônicas, as máquinas fotocopiadoras, os tradutores eletrônicos, as impressoras e os computadores, com suas mídias móveis.

Esses recursos tecnológicos favoreceram o processo de ensino, pelo menos naquelas escolas que puderam arcar com os custos de aquisição dos equipamentos e tiveram sucesso ao engajar seus professores em processos de atualização para o uso desses materiais. Ainda assim, e diante da mudança acelerada para a sociedade da informação, o modelo educacional transmissivo mostrou-se superado e com elevada inércia, desacomodando os estudantes, que já não se mostram culturalmente dispostos a tolerá-lo, "já que as informações se tornaram disponíveis virtualmente a qualquer instante" (MERCADO, 1998), enquanto a escola insiste em práticas como a memorização e a reprodução.

Ao longo da história, portanto, avanços tecnológicos revolucionaram hábitos e as formas como o homem se relaciona com o ambiente. No entanto, a escola permanece utilizando um sistema clássico de ensino que já não supre as demandas sociais. "É fundamental, assim, que se estabeleçam mudanças significativas na prática docente" (PAPERT, 1994), permitindo o surgimento de novas formas de aprender e ensinar, modernizando a escola também pela inclusão das novas tecnologias.

Além do uso intensivo de recursos tecnológicos na educação, entretanto, é necessário preparar os estudantes para o trabalho cooperativo, porque o enfrentamento dos problemas complexos do mundo pós-moderno se faz quase que exclusivamente por meio da cooperação interdisciplinar, que somente vinga no contexto de uma atitude transdisciplinar de aceitação, de tolerância e respeito ao outro e seus conhecimentos, ou seja, em uma interdisciplinaridade do tipo transdisciplinar (GALLON, 2015; MEDEIROS, 2016; FLORES, 2016). Por isso, as estratégias colaborativas de aprendizagem em ambientes virtuais são tão relevantes - em associação ao uso de recursos tecnológicos, a educação pode ampliar as capacidades interativas e cooperativas dos estudantes.

Por tudo o que foi discutido nesta Introdução, então, a pesquisa aqui descrita foi planejada e realizada em uma escola estadual, localizada na região metropolitana de Porto Alegre, e teve como objetivo identificar como os próprios estudantes entendem que o uso de ambientes virtuais de aprendizagem pode contribuir para a construção de práticas colaborativas e tecnológicas no ensino de ciências da natureza. A escola onde estudam os participantes desta investigação está inserida em uma zona de alta vulnerabilidade social, com predomínio de famílias que vivem da agricultura em pequenas propriedades. Participaram da pesquisa 16 alunos do terceiro ano do ensino médio, com idades entre 17 e 22 anos. A pesquisa teve caráter qualitativo e de estudo de caso, e os dados foram analisados pela metodologia Análise Textual Discursiva (ATD).

\section{Reflexões teóricas}

Nas últimas décadas, os recursos disponibilizados pelas Tecnologias de Informação e Comunicação vêm sendo amplamente pesquisados, pois sua utilização tem se disseminado na população, o que promoveu mudanças também na área educacional. Uma das constatações que se pode fazer é que as mudanças tecnológicas têm levado a uma acentuada alteração no modo como as pessoas pensam o mundo e concebem culturalmente a tecnologia (SILVA; PAULA, 2013), o que implicou reflexos na área educacional. Dessa forma, tornou-se conveniente investigar de que modo o fenômeno sociocultural da disseminação das tecnologias de 
informação e comunicação pode influenciar positivamente os processos de ensino e de aprendizagem, utilizando esses resultados em favor da melhoria do ensino.

Essa influência pode ocorrer pela utilização de ambientes virtuais de aprendizagem colaborativos, consistindo em uma oportunidade para o conhecimento ser desenvolvido e partilhado por meio de interações sociais, aplicando, entre outras ferramentas, a elaboração de textos. Esses ambientes tendem a potencializar o processo de elaboração do conhecimento justamente porque incluem ações que estimulam práticas reflexivas e reconstrutivas (DEMO, 2011), como a experiência da produção escrita. É decisivo, porém, que os recursos tecnológicos não se tornem instrumentos de disseminação do modelo instrucionista, entendido como aquele que conserva o aluno como simples acumulador e reprodutor do conhecimento.

Embora a elaboração do conhecimento possa se dar de forma individual, quando o sistema de ensino adota essa diretriz, mesmo implicitamente, estabelece uma "aprendizagem competitiva" (POZO, 2002, p. 47) que valoriza o sucesso privado e produz o fracasso coletivo. A aprendizagem competitiva prioriza a percepção individual e a perspectiva disciplinar do objeto de estudo, obstaculizando o surgimento de visões criativas e compreensões distintas acerca das particularidades, mais bem percebidas pela integração dos olhares de diferentes sujeitos. No caso da aprendizagem, os processos coletivos são sempre melhores, pois as múltiplas compreensões de um mesmo fenômeno tendem a se complementar, colaborando para a ampliação e a complexificação da compreensão de um grupo sobre determinado tema de estudo.

Além disso, a aprendizagem colaborativa estreita as relações sociais e reduz a discriminação e o preconceito, pois cria oportunidades para que cada um possa se manifestar indistintamente, sendo que apenas o conhecimento é colocado sob julgamento e crítica - não a pessoa. Essa é uma manifestação da unidade na diversidade e pressupõe que as interações proporcionem ao grupo oportunidades de modificação de atitudes, o que viabiliza o desenvolvimento pelo viés sociointeracionista.

Em acréscimo, dado que o pensamento sociocultural tende a ser mais complexo, além de fundar um ideal inclusivista (SANTANA, 2008), uma metaconsciência surge à proporção que os indivíduos se tornam mais socializados, da mesma forma que ocorre com as crianças, cujos mundos e pensamentos se irradiam para o exterior a partir de seus egos, assimilando o caráter social da existência e do meio cultural circundante. O rumo do desenvolvimento metacognitivo, portanto, afasta-se do individual em direção às práticas do grupo (FRAWLEY, 2000). Ainda assim, o meio social nunca é estático, mas, sim, está em constante mudança oriunda do próprio processo de interação entre os sujeitos, e deles com o meio.

A aprendizagem colaborativa, portanto, promove a constante interação do sujeito com o grupo, o que faz com que sua compreensão se modifique e, consequentemente, transforme-se continuamente a compreensão do grupo, e vice-versa. Esse processo permanente de desconstrução e reestruturação dos pensamentos individual e coletivo pode colaborar para a aprendizagem, pois:

Tudo pode ser educado e reeducado no ser humano por meio da influência social correspondente. A própria personalidade não deve ser entendida como uma forma acabada, mas como uma forma dinâmica de interação que flui permanentemente entre o organismo e o meio (VYGOTSKY, 2003, p. 17). 
Essa atividade dinâmica e interativa do sujeito com o meio proporciona ao educando a possibilidade de formação colaborativa, que é antagônica ao que propõe a aprendizagem individualizada, que prioriza a particularidade em detrimento da totalidade. A interação colaborativa desenvolve não somente os aspectos cognitivos, de forma reflexiva entre seus pares, mas também seus aspectos comportamentais. Isso fica explícito em Vygotsky, quando este expõe que a personalidade do sujeito é uma estrutura dinâmica, fruto de uma interação constante e construtiva com o meio social onde este se insere. Nas palavras do autor:

Primeiro no nível social, e, depois, no nível individual; primeiro entre pessoas, e, depois, no interior da criança. Isso se aplica igualmente para atenção voluntária, para a memória lógica e para a formação de conceitos. Todas as funções superiores originam-se das relações reais entre indivíduos humanos (VYGOTSKY, 1998, p. 75).

A educação colaborativa é útil sempre, especialmente quando trabalham juntos indivíduos com diferentes aptidões, pois esse desequilíbrio estimula cada qual a buscar o melhor de si, oportunizando a ampliação de suas competências, ao mesmo tempo em que oferece aos mais aptos a oportunidade de compartilhar e reconstruir seus saberes, ensaiando suas habilidades didáticas e de comunicação. Além disso, o exercício de atividades cooperativas tende a produzir resultados mais complexos e eficazes, na medida em que considera e integra diferentes perspectivas.

Os seres humanos são naturalmente gregários, necessitando inserção em um contexto social, e essas relações estão imbricadas com o potencial de aprendizagem, pois o contato proporciona ensinamentos, mesmo que de forma involuntária e informal. A construção colaborativa se acentua na escola, porém, porque as atividades pedagógicas podem proporcionar uma forma orientada de realização desse tipo de prática.

Por isso, a aprendizagem colaborativa é uma tendência, e vem sendo aplicada em associação a jogos e gamificação (DIAS; BORGES; PEREIRA, 2016; MELLO et al., 2019), projetos de aprendizagem (SILVA; MENEZES; FAGUNDES, 2016), monitorias (FRISON, 2016), salas de aulas invertidas (MAZON; SOUZA; SPANHOL, 2016) e em outras situações educacionais.

A educação evolui com a sociedade e está sujeita a uma série de mudanças tecnológicas, metodológicas e filosóficas, entre as quais, atualmente, se situa a utilização dos recursos tecnológicos computacionais e suas estratégias. No entanto, não se deve reduzir a questão educacional ao sucesso ou ao insucesso do uso das tecnologias. O que se pode fazer é garantir que esses recursos sejam corretamente utilizados, visando aos fins da educação. Como Demo (2011, p. 87) expõe, “O trágico disso tudo é que as tecnologias em educação são mais facilmente encurraladas em procedimentos instrucionistas e que, consequentemente, enredam-se em trambiques encurtados, atalhos duvidosos".

Em que pesem os descaminhos do uso inadequado dos recursos, a tecnologia associada principalmente aos ambientes virtuais de aprendizagem colaborativa constitui-se em ferramenta que viabiliza a construção do conhecimento, mesmo que os alunos estejam impossibilitados de comparecer à escola. A capacidade de superar a barreira da distância é um atributo inegável do uso da tecnologia, pois "A escola pode estender-se fisicamente até os limites da cidade e virtualmente até os limites do universo" (MORAN, 2015, p. 99).

Em acréscimo, os ambientes virtuais de aprendizagem colaborativa proporcionam ao grupo de trabalho o desenvolvimento de múltiplas habilidades de expressão, podendo incentivar 

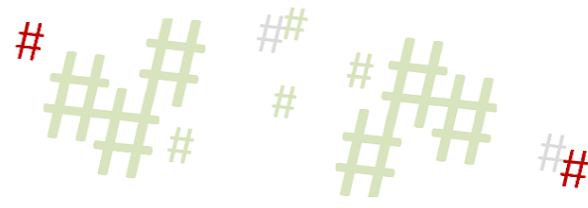

que os estudantes passem a dedicar um tempo ampliado aos estudos, porque em um grupo de colaboração é possível contribuir para a construção do trabalho cooperativo em qualquer lugar e tempo, sem a limitação do espaço escolar e do horário das aulas. Trata-se de uma reinvenção do processo educativo escolar, pois:

\begin{abstract}
O ensino mediado pelas tecnologias digitais redimensiona os papéis de todos os envolvidos no processo educacional. [...] em um mundo que muda rapidamente, professores procuram auxiliar seus alunos a analisar situações complexas e inesperadas; a desenvolver a criatividade; a utilizar outros tipos de 'racionalidade': a imaginação criadora (KENSKI, 2012).
\end{abstract}

Por fim, o exercício da colaboração entre membros de um grupo e até mesmo entre grupos na resolução de simulações e de problemas reais implica diretamente no desenvolvimento de habilidades e competências individuais úteis para a vida na contemporaneidade. Portanto, ao se estimular a aprendizagem colaborativa são produzidos benefícios para todos e para cada um.

\title{
3 Procedimentos Metodológicos
}

A investigação descrita aqui teve uma abordagem qualitativa do tipo estudo de caso, ou seja, foi fundamentada no princípio de uma relação ampla entre os participantes da pesquisa, o pesquisador e o tema estudado, abrangendo uma situação específica de um grupo de participantes, em uma escola, não sendo restrita a processos quantitativos (FREITAS; JABBOUR, 2011). A pesquisa qualitativa se caracteriza por priorizar a análise global de um fenômeno, o que pode favorecer o entendimento do caráter complexo do foco do estudo, conforme descrito por Morin (2013, p. 3) no seguinte excerto:

[...] O desafio da complexidade reside no duplo desafio da religação e da incerteza. É preciso religar o que era considerado como separado. Ao mesmo tempo, é preciso aprender a fazer com que as certezas interajam com a incerteza. O conhecimento é, com efeito, uma viagem que se efetiva em um oceano de incerteza salpicado de arquipélagos de certeza.

A investigação se desenvolveu com alunos de uma turma de terceiro ano do ensino médio, em uma escola pública estadual situada na região metropolitana de Porto Alegre, em uma área rural. Participaram da pesquisa dezesseis indivíduos com idades entre dezesseis e vinte e dois anos. O corpo docente da escola se demonstrou receptivo quanto à realização da pesquisa na instituição, que tem repetidas vezes recebido pesquisadores que buscam acolhimento para realização de suas investigações. Além disso, tanto o corpo docente como o discente reconhecem as contribuições que os trabalhos de pesquisa podem ter para o desenvolvimento dos alunos e para a constituição de uma comunidade escolar mais reflexiva e construtiva.

A instituição escolar investigada possui uma estrutura física e de equipamentos que viabilizou a execução desta pesquisa. Na escola há dois laboratórios de informática nos quais existem desktops conectados à internet; há, também, quarenta e quatro notebooks que podem ser usados pelos alunos em sala de aula, e que se conectam à internet pela rede wi-fi aberta disponível na escola. 
Além disso, a instituição procura manter contato com diferentes universidades e receber informações sobre novas práticas, dedicando-se a realizar parcerias com vistas a aproximar seus alunos do mundo acadêmico. A escola promove alguns projetos interdisciplinares, desenvolvidos trimestralmente pelas diversas áreas do conhecimento, e muitas dessas práticas são apresentadas nos salões e mostras científicas nas universidades parceiras.

Pela conversa com alunos e professores, e pela análise dos últimos livros de ocorrências da instituição, pode-se afirmar que o clima escolar é pacífico, e há um bom entendimento no ambiente interno, com aulas que transcorrem sem interferências. As pessoas alegam, porém, que enfrentam certa dificuldade para manter o ritmo escolar devido às constantes ocorrências criminais nos arredores, que repercutem fortemente na assiduidade. Em situações mais graves as aulas são interrompidas e os alunos, dispensados. Os problemas mais comuns na comunidade estão ligados à violência, que às vezes impede o funcionamento escolar por vários dias. Apesar disso, a comunidade que cerca a escola percebe e valoriza seus espaços, pois o interior da instituição é, segundo parece aos alunos e professores, uma zona mais ou menos livre de perigos. Durante a realização da investigação, porém, não se ouviu notícia de turbulências sociais próximas.

A pesquisa foi executada a partir de uma unidade de aprendizagem que teve por finalidade a construção de conhecimentos acerca do tema dos ambientes virtuais. Essa prática pedagógica visou a distanciar-se do processo linear previsto em grande parte dos currículos. Uma unidade de aprendizagem:

Consiste, portanto, em um conjunto de atividades selecionadas para o estudo de um tema específico ou interdisciplinar, com vistas à reconstrução do conhecimento dos participantes, bem como ao desenvolvimento de habilidades e atitudes. Com o propósito de promover aprendizagens significativas, a UA tem forte relação com as ações de pesquisa, pois se propõe a problematizar o conhecimento inicial dos alunos, desenvolver um questionamento dialógico e reconstrutivo, reconstruir argumentos e promover a comunicação, em especial a fala e a escrita, valorizando a função epistêmica desses processos (MORAES; GALIAZZI; RAMOS, 2004 p. 24).

A unidade de aprendizagem auxilia os educandos no processo de elaboração argumentativa, facilitando que o sujeito constitua produções textuais próprias acerca do tema desenvolvido. $\mathrm{O}$ exercício reconstrutivo de organizar a argumentação é fundamental para o desenvolvimento das capacidades crítica e argumentativa.

Por outro lado, a metodologia utilizada na análise de dados foi a ATD. Essa técnica de análise se presta para quaisquer tipos de dados que possam ser reescritos, classificados e agrupados. O objetivo dessa metodologia, segundo Moraes e Galiazzi (2014, p. 8), é “[...] produzir novas compreensões sobre os fenômenos e discursos". Essas novas compreensões surgem ao longo do processamento analítico, e são resultantes da interação entre o pesquisador, o conhecimento da área e o conjunto de textos analisados, sendo que este fato impõe certa responsabilidade ao investigador, na medida em que é preciso considerar que a percepção da totalidade deve guiar a produção dos resultados parciais da análise. Isso emana da necessidade da compreensão dos sentidos que, segundo Moraes e Galiazzi (2014, p. 14), surge dos textos que são assumidos como significantes, em relação aos quais é possível exprimir significados simbólicos.

Durante os encontros com os participantes foram aplicados questionários estruturados acerca do uso de recursos tecnológicos em sala de aula, assim como de processos de 
colaboração on-line, perguntas semiestruturadas e diário de campo, que se constituíram instrumentos para obtenção de dados. Também se fez a divisão dos participantes em grupos de trabalho, compostos por quatro integrantes que receberam codificação por letras, a fim de preservar suas identidades. Cada um dos grupos recebeu um nome que segue a proposta alquímica da divisão da natureza em quatro elementos: Terra, Água, Fogo e Ar.

\subsection{Encontros presenciais e virtuais}

No primeiro encontro houve uma atividade de apresentação. Foi explicada a importância das pesquisas na área da educação, e como se realizaria ali uma pesquisa, além de qual a possível contribuição dessa pesquisa para a sociedade. Nesse encontro também foi aplicado um questionário que teve por objetivo identificar os conhecimentos prévios dos participantes, assim como suas experiências individuais no uso de ambientes colaborativos, bem como conhecer um pouco das histórias de vida dos indivíduos e sondar o impacto da comunidade e seus diversos problemas sociais nesses indivíduos. Essa prática possibilitou que os indivíduos se aproximassem do objetivo de formar um vínculo com os pesquisadores, que foram tutores do trabalho on-line descrito a seguir.

O questionário inicial foi composto por perguntas objetivas ordenadas numericamente. Seguem, na Tabela 1, as questões e uma análise quantitativa das respostas obtidas por meio da aplicação do instrumento de verificação prévia de conhecimentos.

Tabela 1 - Tabela de conhecimentos prévios acerca do uso de ambientes virtuais

\begin{tabular}{|l|c|}
\hline Questão 1 - Você já ouviu falar do software "OneDrive®"? \\
\hline Sim (50\%) & Não (50\%) \\
\hline Questão 2 - Você já usou o software "OneDrive®"? & Não (81\%) \\
\hline Sim (19\%) & Não (50\%) \\
\hline Questão 3 - Você já ouviu falar de colaboração on-line? & Não (86\%) \\
\hline Sim (50\%) & \\
\hline Questão 4 - Você já colaborou on-line? & Não (82\%) \\
\hline Sim (14\%) & \\
\hline Questão 7 - Você já jogou em rede? & \\
\hline Sim (18\%) &
\end{tabular}

Fonte: PACHECO, LAHM, ROCHA FILHO, 2019.

No segundo encontro ocorreu a atividade de cadastros e prática. Nesse encontro houve um momento de explicações sobre a dinâmica do trabalho colaborativo com uso de recursos tecnológicos, e as dúvidas referentes a essa prática pedagógica foram examinadas. Foi explicitada a necessidade de divisão dos dezesseis participantes em grupos de quatro integrantes. Houve, então, a formação de quatro grupos: Primeiro Grupo: Água; Segundo Grupo: Fogo; Terceiro Grupo Terra, e; Quarto Grupo: Ar.

Após a divisão, os alunos foram convidados a se realocarem nos grupos e a preencherem uma tabela com seus respectivos e-mails. Alguns indivíduos não possuíam uma conta de e-mail, então foram disponibilizados notebooks de propriedade da escola para que eles realizassem cadastramento em um serviço de e-mail, a fim de poderem receber a senha e o login de acesso 
para ingressarem no grupo de colaboração. Após os participantes serem cadastrados no serviço de construção colaborativa em nuvem, receberam os e-mails com o link da pasta de trabalho, a partir da qual poderiam efetuar as discussões acerca do tema.

Para a construção dos processos de colaboração foi proposta uma apresentação com auxílio de um projetor, por meio do qual os diversos recursos puderam ser explicitados e discutidos com os alunos. Durante essa apresentação os estudantes se organizaram em grupos e expuseram suas dúvidas acerca da apresentação, sendo estimulados a descrever seus anseios e dúvidas acerca das atividades. Por fim, foi esclarecido que os encontros virtuais não ocorreriam em dias e horários fixos, mas, sim, de forma assimétrica e, predominantemente, no final da tarde, e mais ainda no turno da noite, já que grande parte dos alunos participantes desta pesquisa estagiam no turno da tarde.

Após a formação dos grupos, os alunos foram convidados a formar um círculo e se assentarem no chão, narrando algo que julgassem importante em suas histórias de vida, podendo ser uma experiência pessoal ou um relato de uma contemplação. Essa prática teve por objetivo conhecer um pouco mais da história dos sujeitos que participaram da pesquisa, seus desejos de futuro, bem como estimular e possibilitar que os indivíduos se aproximassem e formassem vínculos. Fez parte desta análise descobrir aspectos do cotidiano desse grupo de alunos que vive em uma comunidade reconhecida pela violência.

Os discursos se seguiram durante aproximadamente cinquenta minutos, em momentos transformadores e de muita expectativa por parte dos ouvintes, que se depararam com realidades distintas e marcantes. A troca de experiências é uma forma colaborativa de construção da afetividade e da fraternidade, e ficou clara a empatia demonstrada nas expressões faciais dos participantes ao ouvirem os relatos de seus colegas, que às vezes se transformavam em lágrimas. Os participantes não desejavam o fim daquela experiência quando soou o sinal indicando o término do encontro. Eles deflagraram uma sequência de pedidos para que a prática continuasse, pois todos se sentiram confortáveis em compartilhar suas histórias. O chão tornouse uma poltrona, e os olhos denunciavam as expectativas enquanto as declarações se desenrolavam.

O terceiro encontro foi denominado de atividades não presenciais. Dado início ao processo de colaboração, os encontros virtuais passaram a ocorrer cotidianamente, abordando os temas de trabalho previamente definidos para cada grupo. À medida que os grupos colaboravam, mensagens instantâneas de alerta de modificação eram enviadas para os pesquisadores, que acompanharam, dessa forma, o processo colaborativo.

A investigação evidenciou que a colaboração parece reduzir a separação hierárquica entre o professor e os alunos. Durante todo o processo o professor pode se inteirar acerca da aprendizagem e do andamento dos trabalhos, possibilitando que o processo de reconstrução seja contínuo. Durante os encontros virtuais foi possível acompanhar em tempo real quantos e quais alunos trabalhavam on-line, o que produziam ou quais atividades realizavam, visualizando suas produções, como, por exemplo, imagens, vídeos e textos.

O fluxo de produção foi conduzido pelos alunos. Eles instituíram esse fluxo a partir de um esquema de discussões e organização das ideias sobre o tema, fazendo com que os percalços gerados pelos desconhecimentos fossem logo sanados por meio do estudo, da pesquisa e das opiniões de outros membros do grupo. Os debates em torno dos assuntos foram amplamente amparados por imagens e textos, estruturando o crescimento argumentativo e a complexificação dos conhecimentos. Constantes modificações de conceitos empíricos foram produzidas por meio da construção coletiva, onde o conhecimento pôde ser questionado e reconstruído. 
O quarto encontro foi a finalização da etapa de colaboração, e por isso foi denominada de atividade final. Os dezesseis participantes foram organizados em grupos e convidados a compartilharem as experiências vividas durante a prática colaborativa. As discussões emergiram por meio de debates entre grupos. Inicialmente, as falas foram estimuladas pelos pesquisadores, mas, a partir disso, os sujeitos passaram a descrever as experiências obtidas durante a pesquisa, o que estabeleceu uma forma produtiva de construção recíproca. As argumentações de cada grupo cooperaram com as discussões sugeridas pelos demais, que debateram a influência da colaboração on-line na aprendizagem.

Entre os temas que emergiram nas discussões dos grupos surgiu a importância da assistência dos professores ou tutores. No trabalho colaborativo há maior necessidade dessa assistência, por meio da qual os professores ou tutores acompanham o desenvolvimento do tema e auxiliam os participantes utilizando-se da mediação. Pode-se depreender isso da declaração do Grupo Fogo: "O trabalho on-line é muito diferente dos trabalhos que se copia e cola, o professor está sempre corrigindo, não dá para copiar e colar, o professor acompanha nossas contribuições e discussões". A mediação implica a ação de uma pessoa norteadora ou moderadora das atividades, com o propósito de evitar a fragmentação dos diálogos bem como a transformação do trabalho colaborativo em uma réplica do modelo instrucionista, baseado em reprodução, sem autoria ou valor reflexivo.

Entre os aspectos positivos destacados está a mobilidade oportunizada pelos recursos tecnológicos, que supera as limitações das práticas colaborativas tradicionais, presas aos espaços físicos e ao tempo sequencial. Dois grupos procuraram, de forma coletiva, descrever o processo de aprendizagem colaborativa por meio de tecnologias de informação, destacando o que julgaram ser positivo no uso dessa ferramenta pedagógica. Esses destaques são evidenciados no relato do Grupo Terra:

\footnotetext{
Podemos produzir muito mais, e é muito fascinante o que podemos aprofundar de ideias com a tecnologia. O conhecimento científico foi beneficiado, falamos sobre as pessoas e as relações delas com o ambiente e o que elas sofrem e passam. Sabe, muita coisa acontece e nem percebemos, mas quando paramos para falar de nós mesmos percebemos nossas diferenças.
}

Procurando-se aprofundar a análise, aplicou-se um questionário semiestruturado aos participantes, no último encontro, cujos resultados são descritos e discutidos a seguir.

\subsection{Discussão e resultados}

Quando foi iniciada a unidade de aprendizagem se detectou que a maioria dos pesquisados não teve contato prévio com ferramentas de colaboração on-line, mas que os participantes ocasionalmente executavam trabalhos de pesquisa que deviam ser feitos em grupo, segundo a proposição dos professores.

Ocorre que a educação que se utiliza de recursos tecnológicos promove a formação não só dos jovens, mas também de todas pessoas envolvidas (KENSKI, 2012, p. 19), o que de forma progressiva envolve todo corpo escolar. Esse movimento participativo e colaborativo é fundamental para a educação, pois demonstra que esta não funciona em modo de via única - o processo de construção de conhecimento é sempre partilhado e coletivo.

Nas respostas ao questionário semiestruturado os alunos expuseram que desconheciam o tema, a exemplo do participante C, que "Nunca tinha ouvido falar deste tipo de trabalho". 
Ainda assim, a cooperação mediada por ambiente virtual colaborativo contribuiu para a aprendizagem, diminuindo o afastamento hierárquico entre o professor e o aluno, conforme se depreende da declaração do participante $\mathrm{D}$, quando escreve que "Na minha perspectiva aproximou mais o professor dos alunos". Os participantes claramente valorizam o acesso privilegiado aos professores e ao grupo, não ficando restritos aos encontros presenciais nas aulas semanais, mas viabilizando maior conectividade entre os alunos, e destes com os professores. A partir da emergência de questionamentos, os mediadores puderam ser acessados imediatamente, dirimindo dúvidas e fazendo com que a comunicação entre alunos e professores se tornasse comum mesmo fora da sala de aula (KENSKI, 2012).

A utilização da tecnologia de informação na escola parece induzir curiosidade, criatividade e capacidade de questionamento, o que é bom, pois estas constituem a base de um trabalho de pesquisa, pois tudo pode ser questionado e problematizado (MORAES; LIMA, 2012). Entre os temas mais frequentemente descritos e debatidos durante a pesquisa esteve o espírito investigativo e questionador, como indicado pelo participante A, quando afirma que "Sim o uso da tecnologia é um instrumento de despertar a curiosidade", ou quando o participante $G$ diz que "A tecnologia possibilita que possamos pensar de forma diferente, questionando e duvidando".

Além disso, o uso combinado dos recursos tecnológicos com o fator presencial facilitou a formação de grupos de trabalho, o que não impediu o surgimento de dificuldades durante o processo online, como o destacado pelo participante $\mathrm{K}$, na manifestação de que "O trabalho é bom, mas nem todos conseguem ter acesso à internet, estes dependem dos computadores e internet da escola, mas mesmo assim vale a pena". A carência de acesso à internet em comunidades mais pobres ainda é grande, e há alunos que não dispõem sequer de um smartphone em casa. Nesta investigação, dois casos dessa natureza foram superados por meio do oferecimento da infraestrutura da escola, e os participantes colaboraram on-line nos períodos de intervalo escolar.

Como uma característica definidora da tecnologia da informação aplicada ao ambiente escolar é a mobilidade, a maioria dos alunos destacou este aspecto do uso dos recursos tecnológicos na execução das atividades. Isso transparece no relato do participante $\mathrm{N}$, quando afirma que "Nos empenhamos bastante, ajudando rapidamente na elaboração e não precisando estar na escola para trabalharmos juntos".

A possibilidade de estudar sem se deslocar à instituição também pode ser um fator favorável, considerando que na comunidade onde a escola se insere por diversas vezes as aulas tiveram de ser suspensas devido à violência. Mesmo enquanto as atividades na escola ficaram comprometidas, o processo colaborativo não cessou na plataforma virtual, conforme o histórico de versão que os pesquisadores puderam acompanhar. Esta ferramenta permite que se acesse a postagem de cada uma das versões do trabalho, identificando o participante e o instante em que foi efetuada.

Por fim, se destaca a expressão individual de cada participante, por meio de suas escritas e de seus relatos, pois a comunicação de suas ideias na forma escrita está impregnada de suas experiências e concepções. Ao longo do trabalho essas experiências foram se misturando e transformando as ideias individuais em coletivas, e dessa forma as ideias foram sendo complexificadas e as experiências, estendidas. Isso contribui para a desconstrução da noção de aluno como alguém que desempenha um papel apenas receptivo no processo educativo (DEMO, 2011). 


\section{Conclusões}

Esta investigação procurou identificar e analisar as contribuições que o uso dos ambientes virtuais de aprendizagem colaborativa - no caso, o OneDrive ${ }^{\circledR}$ - pode trazer para o ensino de ciências da natureza. Por meio do diário de observação e das respostas fornecidas pelos participantes, o presente artigo expôs e discutiu uma proposta de utilização do One Drive ${ }^{\circledR}$ na tessitura de uma aprendizagem colaborativa e reconstrutiva. Um relato descritivo relacionou o uso desse recurso tecnológico com as impressões dos participantes, facilitando a implementação de uma proposta de construção compartilhada.

Os principais argumentos favoráveis ao uso das práticas colaborativas por parte dos participantes de pesquisa foram:

a) o estímulo ao trabalho de pesquisa e valorização dessa proposta;

b) o desenvolvimento social na construção colaborativa;

c) a necessidade da integração e adaptação das práticas escolares ao uso de tecnologia;

d) a aproximação entre os alunos;

e) a acessibilidade do professor ao acompanhamento da aprendizagem, e;

f) o fato de os alunos não estarem presos aos processos desenvolvidos apenas em sala de aula, desta forma contemplando a mobilidade, que tem papel proeminente ao possibilitar o contato e a construção do conhecimento.

A unidade de aprendizagem, por sua vez, envolveu atividades presenciais e atividades executadas a distância, e os resultados do trabalho de colaboração em sala de aula e a distância foram complementares. $\mathrm{O}$ encontro presencial proporcionou um contato mais estreito entre os participantes, e foi fundamental para o desenvolvimento da empatia no grupo, em uma experiência por eles mesmos relatada ao se engajarem no compartilhamento de experiências e nos trabalhos a distância.

Há obstáculos, porém, à ampliação do uso de ambientes colaborativos via tecnologias da informação nas atividades escolares corriqueiras. Embora de uma forma mais ampla esses obstáculos possam ser separados em "Macro (sistema educativo), Meso (institucional) e Pessoal (professores e alunos)" (MOREIRA; LOUREIRO; MARQUES, 2005, p. 1), no caso específico dos ambientes colaborativos digitais esses entraves podem ser separados em três categorias mais objetivas, para fins de compreensão:

\section{a) Relativos aos estudantes:}

Nem todos os estudantes dispõem de meios materiais mínimos (computador ou smartphone e acesso à internet), necessários para participarem ativamente e com mobilidade de um trabalho cooperativo mediado pelas tecnologias de informação e comunicação (FIORENTIN, 2016).

Embora os jovens sejam nativos digitais e quase sempre estejam familiarizados com essas tecnologias, a simples utilização desses meios pode não ser fonte de convencimento ou motivação quanto à utilidade de estudar determinado tema do ensino básico. Estabelecer essa motivação e interesse a partir do simples uso dos meios tecnológicos pode se tornar gradativamente mais difícil à medida que as tecnologias se difundam e se tornem onipresentes, tornando-se corriqueiras, “[...] ou seja, quando os problemas de acesso psicológico e material 
estiverem resolvidos, os problemas inerentes a habilidades e uso emergem e devem ser tratados" (BELLINI; GIEBELEN; CASALI, 2010, p. 27).

Apesar de que se pode supor que, idealmente, qualquer pessoa possa se interessar por qualquer assunto do currículo escolar, a depender da metodologia utilizada pelo professor, também é compreensível que um professor específico não seja capaz de implementar um espectro de estratégias tão vasto que alcance despertar interesse em qualquer estudante. Além disso, a desmotivação pode provir de fatores exógenos (PAIVA; MORAIS; PAIVA, 2010), de modo que a automotivação, ou motivação intrínseca, é necessária em algum grau.

b) Quanto aos professores:

Nem todos os professores têm o conhecimento mínimo necessário para utilizarem as plataformas virtuais de compartilhamento de informações e trabalho cooperativo, ou disposição (ou tempo) para buscarem esse conhecimento (RODRIGUES, 2014).

Quando o uso da tecnologia, em si, não é suficiente para provocar interesse e motivar os estudantes, o carisma do professor ainda parece ser a fonte básica de motivação extrínseca dos estudantes (MAIA, 2019).

Ao propor um trabalho cooperativo on-line o professor deve estar ciente de que pode ser necessário se manter disponível para orientar alunos a distância por mais horas do que aquelas destinadas às atividades normais do cotidiano escolar (LAPA; PRETTO, 2010). É preciso tempo e disposição para esse trabalho, pois a demora na resposta ao estudante pode causar seu desinteresse pela proposta (CUNHA; SILVA, 2009).

c) Quanto às escolas:

Nem todas as escolas dispõem de computadores para uso dos estudantes, e quando os têm, muitas vezes estes são ultrapassados e lentos. Uma proporção ainda menor de escolas disponibiliza redes de internet sem fio para uso dos estudantes, e aquelas que o fazem, geralmente possuem redes de baixa velocidade de conexão, muitas vezes inviabilizando o uso educacional, restringindo a amplitude das atividades ou o alcance de uma proposta interativa que se baseie no uso de tecnologias de comunicação e informação (SOPRANA, 2017).

Finalizando o presente trabalho investigativo, recomenda-se a ampliação das pesquisas em torno de softwares que insiram os smartphones e computadores no cotidiano educacional, pois é fundamental incentivar o desenvolvimento de trabalhos colaborativos mediados por recursos tecnológicos.

\section{Referências}

ALTOÉ, A.; SILVA, H. O desenvolvimento histórico das novas tecnologias e seu emprego na educação. In: ALTOÉ, A.; COSTA, M. L. F.; TERUYA, T. K. (Org.). Educação e Novas

Tecnologias. Maringá: Eduem, 2005, p. 13-25.

BELLINI, C. G. P.; GIEBELEN, E.; CASALI, R. R. B. Limitações digitais. Informação \& Sociedade, João Pessoa/PB, v. 20, n. 2, 2010.

COUTINHO, C. P.; LISBÔA, E. S. Sociedade da informação, do conhecimento e da aprendizagem: desafios para educação no século XXI. Revista de Educação, Universidade de Lisboa, v. 18, n. 1, p. 5-22, 2011. 
CUNHA, F. O.; SILVA, J. M. C. Análise das dimensões afetivas do tutor em turmas de EaD no ambiente virtual Moodle. In: SIMPÓSIO BRASILEIRO DE INFORMÁTICA NA EDUCAÇÃO-SBIE, 2009, Florianópolis. Anais... Florianópolis: UFSC, 2009, p. 1-10.

DEMO, P. Educar pela pesquisa. Campinas: Editora Autores Associados, 2011.

DEMO, P. Formação permanente e tecnologias educacionais. Petrópolis: Vozes, 2011.

DIAS, C. M.; BORGES, C. F.; PEREIRA, A. M. Construção de jogo como dispositivo para a aprendizagem colaborativa: algumas estratégias. Blucher Design Proceedings, São Paulo, v. 2, n. 6, p. 255-263, 2016.

FIORENTIN, M. J. Tecnologia digital informação e comunicação: possibilidades e desafios na integração das TDIC no processo ensino aprendizagem no centro de jovens e adultos de Itapiranga/SC. 2016. 61 f. Trabalho de conclusão de curso (Especialização) - Centro de Ciências da Educação, Universidade Federal de Santa Catarina, Florianópolis, 2016.

FLORES, J. F. Integração entre cultura científica e cultura artística no ensino de ciências. 2016. 177 f. Tese (Doutorado) - Programa de Pós-Graduação em Educação em Ciências e Matemática, Pontífice Universidade Católica, Porto Alegre, 2016.

FRAWLEY, W. Vygotsky e a ciência cognitiva. Porto Alegre: Artmed, 2000.

FREITAS, M. Letramento digital e formação de professores. Educação em Revista, Belo Horizonte, v. 26, n. 3, p. 335-352, 2010.

FRISON, L. M. B. Monitoria: uma modalidade de ensino que potencializa a aprendizagem colaborativa e autorregulada. Pro-Posições, Campinas, v. 27, n. 1, p. 133-153, 2016.

FREITAS, W. R. S.; JABBOUR, J. C. Utilizando estudo de caso (s) como estratégia de pesquisa qualitativa: boas práticas e sugestões. Revista Estudo \& Debate, Lajeado, v. 18, n. $2,2011$.

GALLON, Mônica. A interdisciplinaridade, pelo olhar de um grupo de professores de ciências da rede municipal de Canoas, RS, Brasil. 2015. 183 f. Dissertação (Mestrado em Educação) - Programa de Pós-Graduação em Educação em Ciências e Matemática, Pontífice Universidade Católica, Porto Alegre, 2015.

SILVA, N. M.G.; PAULA, M. V. G. Escola e cibercultura: breve reflexão acerca do uso das TIC como recurso pedagógico. Revista Polyphonía, Goiânia, v. 23, n. 1, 2013.

KENSKI, V. M. Educação e tecnologias o novo ritmo da informação. São Paulo: Papirus, 2012.

LAPA, Andrea; PRETTO, Nelson De Luca. Educação a distância e precarização do trabalho docente. Em aberto, Brasília, v. 23, n. 84, 2010. 
MAIA, B. O que torna o professor um “bom professor”? Carisma e autoridade na escola pública. Antropolítica Revista Contemporânea de Antropologia, Salvador, n. 43, 2019.

MAZON, M.; SOUZA, M. V.; SPANHOL, F. A sala de aula invertida como modelo para aprendizagem colaborativa: ferramentas e possibilidades na educação superior. Criar Educação, Criciúma, Edição Especial do II Congresso Ibero-Americano, 2016.

MEDEIROS, G. S. Olhar para o sol: concepção da análise fenomenológica hermenêutica. 2016. 59 f. Dissertação (Mestrado) - Programa de Pós-Graduação em Educação em Ciências e Matemática, PUC-RS, Porto Alegre, 2016.

MELLO, J. A. V. B.; DAINARA, L.; GUSMÃO, V. S.; FELICIANO, D. R.; SANTOS, F. Gamificação como alternativa de ensino e interação com a sociedade. Da Investigação às Práticas: Estudos de Natureza Educacional, Lisboa, v. 9, n. 2, p. 31-45, 2019.

MERCADO, L. P. L. Formação docente e novas tecnologias. In: IV CONGRESSO DA REDE IBEROAMERICANA DE INFORMÁTICA EDUCATIVA, 1998, Porto Alegre. Anais [...] Porto Alegre: UFRGS, 1998. p. 1-8.

MORAES, R.; GALIAZZI, M. C. Análise Textual Discursiva. Ijuí: Editora Unijuí, 2014.

MORAES, R.; GALIAZZI, M. C.; RAMOS, M. G. Pesquisa em sala de aula: fundamentos e pressupostos. In: MORAES, R.; LIMA, V. M. R. (Org.). Pesquisa em Sala de Aula: tendências para a Educação em Novos Tempos. Porto Alegre: Edipucrs, 2004, p. 9-24.

MORAES, R.; LIMA, V. M. D. R. Pesquisa em sala de aula. Porto Alegre: Edipucrs, 2012.

MORAN, J. M. A educação que desejamos: Novos desafios e como chegar à. Campinas: Papirus, 2015.

MOREIRA, A. P.; LOUREIRO; MARQUES, L. Percepções de professores e gestores de escolas relativas aos obstáculos à integração das TIC no ensino das ciências. Enseñanza de las Ciencias, Vigo, Número extra, 2005.

MORIN, E. Educação e complexidade: Os sete saberes e outros ensaios. São Paulo: Cortez, 2013.

PAIVA, J.; MORAIS, C.; PAIVA, J. Referências importantes para a inclusão coerente das TIC na educação numa sociedade "sistémica". Educação, Formação \& Tecnologias, Lisboa, v. 3, n. 2, p. 5-17, 2010.

PAPERT, S. A máquina das crianças. Porto Alegre: Artes Médicas, 1994.

POZO, J. I. Aprendizes e mestres: A nova cultura da aprendizagem. Porto Alegre: Artmed, 2002.

RODRIGUES, A. L. Dificuldades, Constrangimentos e Desafios na Integração das Tecnologias Digitais no Processo de Formação de Professores. In: III CONGRESSO 
INTERNACIONAL DAS TIC NA EDUCAÇÃO APRENDIZAGEM ONLINE, 2014, Lisboa. Anais [...], Lisboa: Instituto de Educação da Universidade de Lisboa, 2014, p. 838846.

SANTANA, N. V. Políticas públicas e práticas sociais direcionadas à inclusão de pessoas com deficiência: retrato da realidade do estado da Bahia, início do século XXI. 2008. 166 f. Tese (Doutorado em Ciências Sociais) - Programa de Estudos Pós-Graduação em Ciências Sociais, Pontífice Universidade Católica, São Paulo, 2008.

SCAGNOLI, N. El aula virtual: usos y elementos que la componen. Madrid: Edudistam, 2000.

SILVA, P.; MENEZES, C.; FAGUNDES, L. Aprendizagem colaborativa: desenvolvimento de Projetos de Aprendizagem em ambientes digitais. In: WORKSHOP DE INFORMÁTICA NA ESCOLA, 2016, Uberlândia. Anais [...] Uberlândia: Universidade Federal de Uberlândia, 2016, p. 815.

SIQUEIRA, T. S. S.; PESSANHA, E. C. R.; SILVA, R. B. Inclusão digital: uma reflexão sobre a situação nas escolas públicas brasileiras. In: XIII ENCONTRO VIRTUAL DE DOCUMENTAÇÃO EM SOFTWARE LIVRE E CONGRESSO INTERNACIONAL DE LINGUAGEM E TECNOLOGIA ONLINE, 2016, Belo Horizonte. Anais[...]. Belo Horizonte: Universidade Federal de Minas Gerais, 2016.

SOPRANA, P. Acesso à internet sem fio cresce nas escolas públicas, mas velocidade é desafio. Época, São Paulo, 03 ago. 2017. Seção Experiências Digitais. Disponível em: https://epoca.globo.com/tecnologia/experiencias-digitais/noticia/2017/08/acesso-internet-semfio-cresce-nas-escolas-publicas-mas-velocidade-ainda-e-desafio.html . Acesso em: 23 out. 2019.

TORRES, P. L.; ALCANTARA, P. R.; IRALA, E. A. F. Grupos de consenso: uma proposta de aprendizagem colaborativa para o processo de ensino-aprendizagem. Revista Diálogo Educacional, Curitiba, v. 4, n. 13, p. 129-145, 2004.

VARELlA, P. G.; VERMELHO, S. C.; HESKETH, C. G.; SILVA, A. C. C. Aprendizagem colaborativa em ambientes virtuais de aprendizagem: a experiência inédita da PUCPR.

Revista Diálogo Educacional, Curitiba, v. 3, n. 6, p. 11-27, 2002.

VYGOTSKY, L. S. A formação social da mente: o desenvolvimento dos processos psicológicos superiores. São Paulo: Martins Fontes, 1998.

VYGOTSKY, L. S. Psicologia pedagógica. Porto Alegre: Artmed, 2003.

VYGOTSKY, L. S. Mind in Society: The Development of Higher Psychological.

Cambridge: Harvard University Press, 1978.

Recebido em agosto de 2019.

Aprovado em outubro de 2019. 